\title{
Roadmap to NRC Approval of Ceramic Matrix Composites in Generation IV Reactors
}

\author{
M.G. Jenkins \\ E. Lara-Curzio \\ W. Windes
}

May 2006

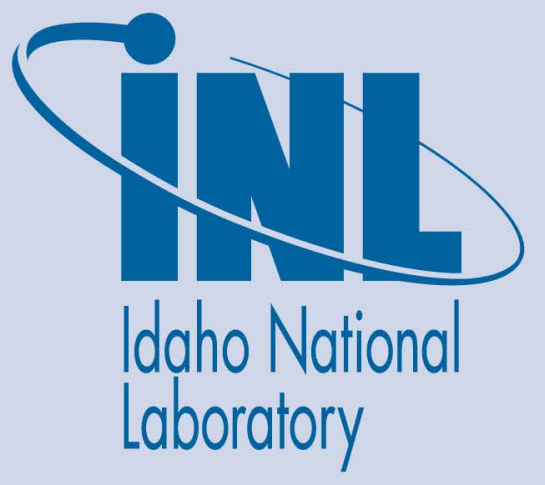

The INL is a U.S. Department of Energy National Laboratory operated by Battelle Energy Alliance 
INL/EXT-06-11425

\title{
Roadmap to NRC Approval of Ceramic Matrix Composites in Generation IV Reactors
}

\author{
M.G. Jenkins ${ }^{a}$ \\ E. Lara-Curziob \\ W. Windes ${ }^{c}$
}

aUniversity of Detroit Mercy

${ }^{b}$ Oak Ridge National Laboratory

'Idaho National Laboratory

May 2006

\section{Idaho National Laboratory \\ Idaho Falls, Idaho 83415}

Prepared for the

U.S. Department of Energy

Office of Nuclear Energy

Under DOE Idaho Operations Office

Contract DE-AC07-05ID14517 
This page intentionally left blank. 


\section{Executive Summary}

Ceramic matrix composites (CMCs) are candidate advanced materials for Generation IV (GenIV) nuclear power applications because of their excellent retention of mechanical properties at elevated temperatures and their low activation when subjected to neutron irradiation. Continuous fiber-reinforced CMCs exhibit greatly increased "toughness" (i.e., nonlinear energy dissipation during deformation) and, therefore, provide the inherent damage tolerance and increased reliability that are critical in many engineering applications where the brittleness of conventional advanced ceramics leads to unacceptable modes of failure. However, the uniqueness of CMCs often makes conventional testing and design methodologies inappropriate. Additionally, the relative scarcity of CMC standards (i.e., test methods, classification systems, unified terminology, and reference materials) and the lack of CMC design codes and their related databases are limiting factors in obtaining regulatory acceptance and approval to use CMCs in GenIV and other nuclear power applications.

This report provides an initial roadmap to obtain Nuclear Regulatory Commission (NRC) approval for using these material systems in a nuclear application. The roadmap follows a chronological progression based on increasing sophistication of the critical building blocks necessary for developing a code case for CMCs. In other words, full consensus standards must first be developed to characterize basic billets of materials. Databases must next be developed to produce valid, statistically-significant property and performance data using the recognized, full-consensus standards. Design codes and life prediction methodologies must then be developed based on the unique design requirements of the materials and design applications. Inherent in the design codes are fully qualified materials properties and performance databases determined using full consensus standards. Finally, regulatory approval is achieved once the material, components, and design methodologies have been established, validated, and documented.

This report is a "snap-shot" of the perceived path-forward for achieving NRC approval of ceramic composites in a nuclear application. The possible paths taken to achieving NRC approval are necessarily subject to change as this is an on-going process that shifts as more data and a clearer understanding of the nuclear regulations are gathered. As such, supplemental progress reports will be required to clarify specific decisions and paths taken based upon future results and NRC/American Society of Mechanical Engineers (ASME)/American Society for Testing and Materials (ASTM) regulations. 


\section{Contents}

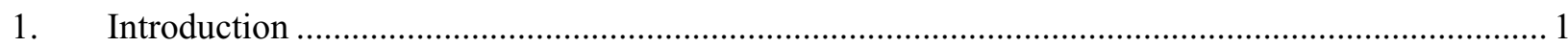

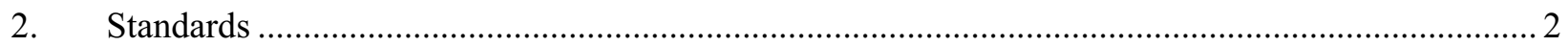

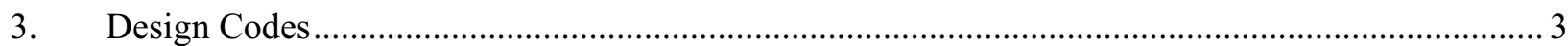

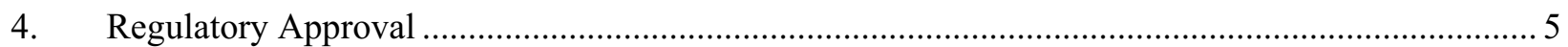

\section{Figures}

Figure 1 Interrelation among Standards, Databases, Design Codes and Regulatory Approval ......1

Figure 2 Steps in the ASTM and ISO standards balloting processes ......................................

Figure 3. Schematic illustration of "design by analysis" approach for CMCs where timedependent performance of components is predicted using long-term performance of materials measured using standards. 


\section{Acronyms}

$\begin{array}{cl}\text { ASME } & \text { American Society of Mechanical Engineers } \\ \text { ASTM } & \text { American Society for Testing and Materials } \\ \text { CEN } & \text { Comité Européen de Normalisation } \\ \text { CMCs } & \text { Ceramic matrix composites } \\ \text { GenIV } & \text { Generation IV } \\ \text { HSR/EPM } & \text { NASA High Speed Research/Enabling Propulsion Program } \\ \text { ISO } & \text { International Organization for Standardization } \\ \text { NRC } & \text { Nuclear Regulatory Commission } \\ \text { PEC } & \text { Petroleum Energy Center }\end{array}$




\section{Roadmap to NRC Approval of Ceramic Matrix Composites in Generation IV Reactors}

\section{Introduction}

Ceramic matrix composites (CMCs) are candidate advanced materials for Generation IV (GenIV) nuclear power applications because of their excellent retention of mechanical properties at elevated temperatures and their low activation when subjected to neutron irradiation. CMC materials possess many of the critical characteristics of advanced ceramic monoliths (e.g., low density, high stiffness, elevated temperature capability, etc.) while exhibiting increased "toughness" over their monolithic counterparts. Continuous fiber-reinforced CMCs exhibit greatly increased "toughness" (i.e., nonlinear energy dissipation during deformation) and, therefore, provide the inherent damage tolerance and increased reliability that are critical in many engineering applications where the brittleness of conventional advanced ceramics leads to unacceptable modes of failure.

The uniqueness of CMCs often makes conventional testing and design methodologies inappropriate, and the characterization and development of models to predict the thermo-mechanical behavior of CMCs has become the subject of extensive investigations worldwide. As CMC prototype and trial products become available, the relative scarcity of CMC standards (i.e., test methods, classification systems, unified terminology, and reference materials) and the lack of CMC design codes and their related databases are limiting factors in obtaining regulatory acceptance and approval to use CMCs in GenIV and other nuclear power applications. Figure 1 illustrates the interrelation of CMC components, standards, design codes, databases, regulation, and GenIV reactors.

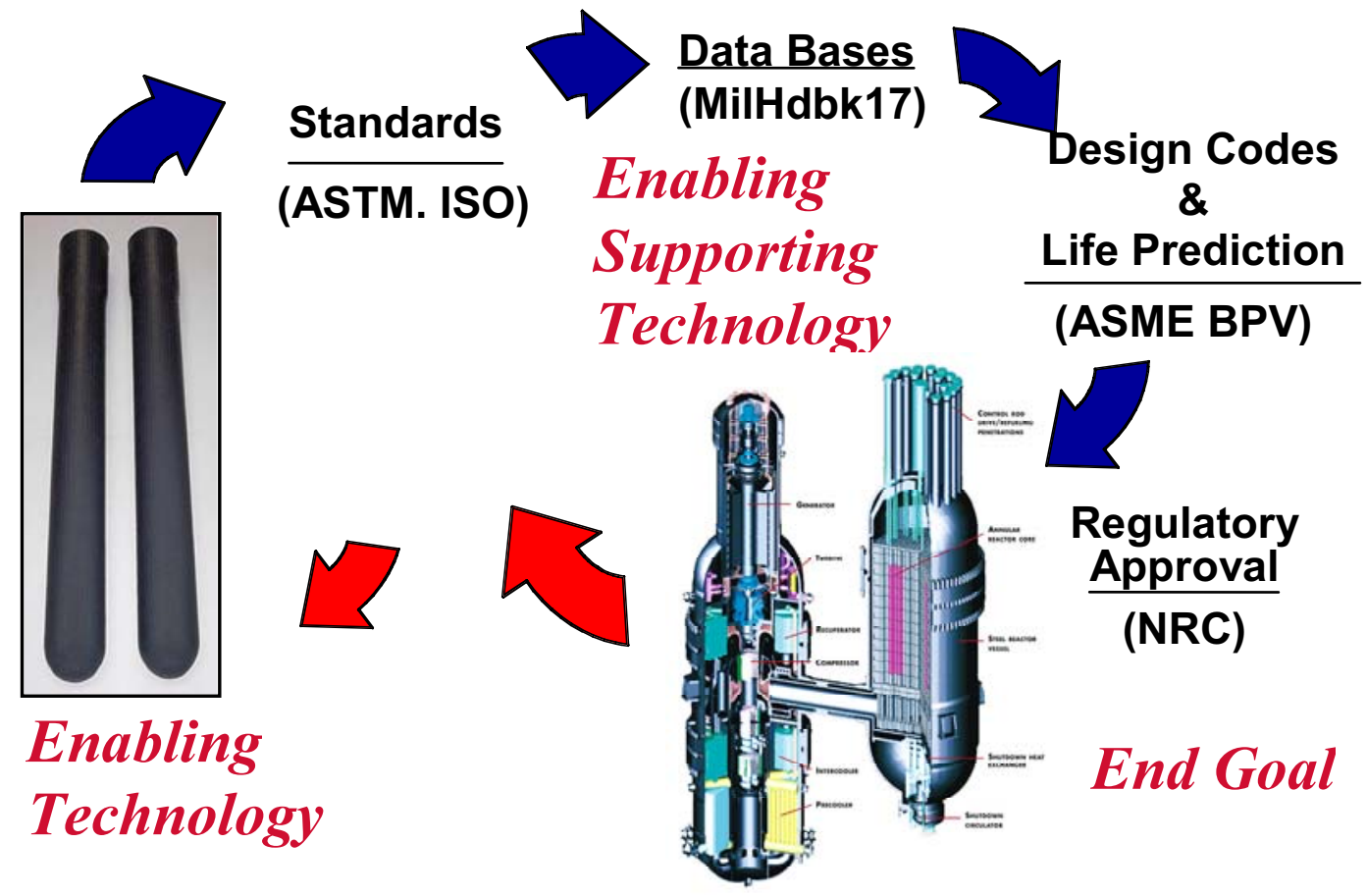

Figure 1. Interrelation of Standards, Databases, Design Codes, and Regulatory Approval 
The development of each of the steps shown in Figure 1 follows a chronological progression based on increasing sophistication of the critical building blocks. In other words, full consensus standards must first be developed to characterize basic billets of materials. Databases must next be developed to produce valid, statistically-significant property and performance data using the recognized, full-consensus standards. Various levels of significance are assigned to the information contained in the database, namely, Screening, Preliminary, and Fully Qualified. Design codes and life prediction methodologies must then be developed based on the unique design requirements of the materials and design applications. Inherent in the design codes are fully qualified materials properties and performance databases determined using full consensus standards. Life prediction methodologies are an integral part of these design codes. Finally, regulatory approval is achieved once the material, components, and design methodologies have been established, validated, and documented.

\section{Standards}

As a technical term, "standards" has multiple interpretations. For example, for researchers or for those in the technical community "standards" may indicate units of measure and/or fundamental test methodologies. For manufacturers or end-product users, "standards" may indicate materials specifications and tests needed to meet requirements. Commercial standards equate to the rules or terms of information transfer between designers, manufacturers, and product users. Differences even exist between the levels of standards within a given area of applicability, for example, company (internal use and consensus), industry (trade use with limited consensus), government (wide use and various levels of consensus), and full-consensus (broadest use and greatest consensus). In the context of the current effort, there are few national or international full-consensus standards for evaluating CMCs.

Technical and pragmatic issues related to standardization efforts for CMCs have been addressed in full-consensus standards:

- American Society for Testing and Materials (ASTM) Subcommittee C28.07 on Ceramic Matrix Composites

- Comité Européen de Normalisation (CEN) Subcommittee TC184/SC1 on Ceramic Composites

- International Organization for Standardization (ISO) Technical Committee TC206 on Fine (Advanced, Technical) Ceramics.

In addition, other noteworthy, non full-consensus standards for CMCs have been developed by the NASA High Speed Research/Enabling Propulsion Program (HSR/EPM) in the United States and the Petroleum Energy Center (PEC) in Japan. Despite these widespread efforts, the lack of standards specific to GenIV $\mathrm{CMC}$ applications (i.e., tubes under complex modes of loading that include tension, compression, internal pressure, torsion, and flexural) will limit the ability to evaluate CMCs on a common-denominator basis and may hamper further material development. In particular, the steps required to develop a fullconsensus national or international standard follow multiple levels of balloting over a 6- to 18-month period before final approval is given (see Figure 2). 


\section{ASTM (6 to 12 months)}

New Work Item (Task group formed, title)

Subcommittee Ballot (Draft document submitted to subcommittee only)

Concurrent Main and Subcommittee Ballots (Refined document submitted to sub and main committees)

Society Review (Refined document available for society)

ASTM Standard

\section{$\underline{\text { ISO (12 to } 18 \text { months) }}$}

Stage 0 (preliminary stage): A study period is underway.

Stage 1 (proposal stage): An NP (New Project) is under consideration.

Stage 2 (preparatory stage): A WD (Working Draft) is under consideration.

Stage 3 (committee stage): A CD/FCD (Committee Draft/Final Committee Draft) is under consideration.

Stage 4 (approval stage): An FDIS (Final Draft International Standard) is under consideration.

Stage 5 (publication stage): An IS (International Standard) is being prepared for publication.

Figure 2. Steps in the ASTM and ISO standards balloting processes

\section{Design Codes}

Interpretation of the term "design code" is not always clear. In this discussion, "design code" is not a design manual (i.e., a "cookbook" design procedure that results in a desired component or system). Rather, "design codes" are widely-accepted general rules for the construction of components or systems with emphasis on safety. A main objective is the reasonably long safe-life of the design while providing the reasonably certain protection of life and property. While recognizing the needs of the users, manufacturers, and inspectors, the main premise of the codes is that safety of the design can never be compromised.

Because it does not impose specific rules for design, the "design code" allows flexibility for introducing new designs as required for performance, efficiency, usability, or manufacturability while still providing constraints for safety. Such a "design code" is wide ranging and incorporates links between materials, general design (formulae, loads, allowable stresses, permitted details), fabrication methods, inspection, testing, certification, data reports, and quality control to ensure that the "design code" has been followed. Thus, the "design code" inherently contains many of the standards for materials testing, characterization, and quality control. Additionally, unlike standards that do not provide for compliance or accountability, "design codes" require compliance through documentation, and certification through inspection and quality control.

Two efforts are currently underway to establish such design codes for CMCs: (1) the Military Handbook 17 (Mil-Hdbk-17) CMC effort, and (2) the American Society of Mechanical Engineers (ASME) Task Group on Ceramic and Graphite Pressure Equipment of the ASME Boiler and Pressure Vessel Code. Test standards are incorporated in both these efforts to provide common and consensus methods for determining the properties and performance of materials "approved" for use under the design code. 
Of these two efforts, the ASME Task Group is the most appropriate for GenIV applications because of its direct application to pressurized equipment. The ASME Task Group was formed in 1995 due to increasing interest in CMCs from the power generation community along with similar continuing interest in impervious graphite from the chemical processing community. The Task Group specifically addresses the possible explicit introduction of brittle materials (i.e., impervious graphite and ceramic composites [Note: CMCs are not brittle materials]) into the "code" as acceptable, performance-based materials. Subsequent division of the task group resulted in the formation of two subtask groups, with the Subtask Group on Ceramic Pressure Equipment specifically targeted to CMCs. Two possible paths were considered for the subtask group: (1) development of a "code" case to demonstrate that brittle materials have been and are successfully being used in pressurized equipment, and (2) development of a standalone section of the "code." Path 1 was chosen by the Subtask Group on Impervious Graphite because there are many current applications of this material in pressure equipment. CMCs are not currently used in pressurized equipment; therefore, Path 2 was chosen by the Subtask Group on Ceramic Pressure Equipment. A $100+$ page draft of a stand-alone section (cloned from Section X on PMCs) was subsequently developed with the following organization (Note: this draft section also employs reliabilitybased design rather than design by rule or factor of safety design by analysis):

1. Introduction

2. General Requirements

3. Material Requirements

4. Design Requirements

5. Fabrication Requirements

6. Qualification Requirements

7. Pressure Relief Devices

8. Rules Governing Testing

9. Inspection Requirements

10. Marking, Stamping, Reporting

11. Appendices

12. Forms.

Work on this draft section is ongoing and is dependent on development of standards, data bases, and design methodologies that must be completed in parallel with the code work. Figure 3 illustrates the use of a "design by analysis" aspect of a design code in which the long-term performance of a component is predicted using an iterative algorithm that requires, as input, the long-term performance of materials determined using standards.

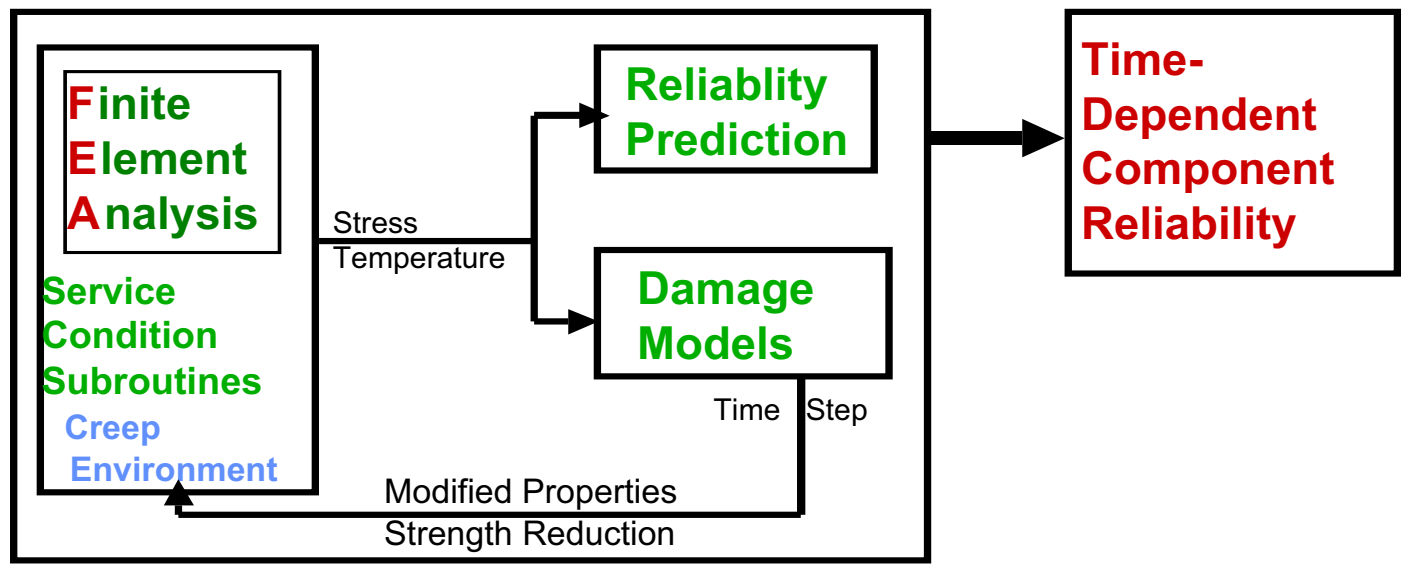

Figure 3. "Design by analysis" approach for CMCs where time-dependent performance of components is predicted using long-term performance of materials measured using standards. 


\section{Regulatory Approval}

The extension of standards to industry-approved and embraced design codes is particularly important for GenIV nuclear applications because of the oversight provided by the NRC. The NRC is an independent agency established by the Energy Reorganization Act of 1974 to regulate civilian use of nuclear materials and, as such, is insistent on documentation, best practices, and rigorous procedures. Design codes along with the standards incorporated in the design code represent debated, balloted, and approved consensus documents that are essential for meeting the approval of the NRC. 